Article

\title{
Satureja montana L. and Origanum majorana L. Decoctions: Antimicrobial Activity, Mode of Action and Phenolic Characterization
}

\author{
Fernanda Gomes ${ }^{1, *}{ }^{(}$, Maria Inês Dias ${ }^{2}{ }^{\circ}$, Ângela Lima ${ }^{1}$, Lillian Barros ${ }^{2}{ }^{\circ}$, \\ Maria Elisa Rodrigues ${ }^{1}$ (D), Isabel C.F.R. Ferreira ${ }^{2} \mathbb{D}$ and Mariana Henriques ${ }^{1}(\mathbb{D}$ \\ 1 CEB, Centro de Engenharia Biológica, LIBRO-Laboratório de Investigação em Biofilmes Rosário Oliveira, \\ Universidade do Minho, 4710-057 Braga, Portugal; pg33053@alunos.uminho.pt (Â.L.); \\ elisarodrigues@deb.uminho.pt (M.E.R.); mcrh@deb.uminho.pt (M.H.) \\ 2 Centro de Investigação de Montanha (CIMO), Instituto Politécnico de Bragança, Campus de Santa Apolónia, \\ 5300-253 Bragança, Portugal; maria.ines@ipb.pt (M.I.D.); lillian@ipb.pt (L.B.); iferreira@ipb.pt (I.C.F.R.F.) \\ * Correspondence: fernandaisabel@ceb.uminho.pt
}

Received: 28 April 2020; Accepted: 29 May 2020; Published: 31 May 2020

\begin{abstract}
Medicinal and aromatic plants are known to have a wide range of uses and health benefits, and should be exploited for their bioactivity. Here we evaluated the antimicrobial activity of decoctions of Satureja montana L. and Origanum majorana L. against Gram-positive and Gram-negative bacteria and Candida spp. as well as their mechanism of action and phenolic characterization. The Satureja montana and Origanum majorana extracts were effective against a broad set of species, including the Gram-positive Staphylococcus aureus, Enterococcus faecalis, and Streptococcus dysgalactiae and the Gram-negative Klebsiella pneumoniae and Pseudomonas aeruginosa. Both extracts were found to have rosmarinic acid as the main phenolic compound and to exert their antimicrobial activity at the level of the cell membrane. Membrane perturbations by the extracts impaired cell membrane integrity only a few hours after exposure. This study confirms the bioactive potential of Satureja montana and Origanum majorana decoctions, and supports the development of novel formulations with wide antimicrobial properties based on these medicinal and aromatic herbs.
\end{abstract}

Keywords: Satureja montana; Origanum majorana; decoction; antimicrobial activity; mechanism of action; phenolic characterization

\section{Introduction}

Vegetables, grains, and fruits are a good source of bioactive molecules, such as flavonoids and phenolic acids [1,2]. In plants, phenolic compounds are part of the natural defense system against several pathogens, such as bacteria, fungi, viruses, and other pests, and also play an important role in the regulation of plant hormones [3]. Polyphenols (phenolic compounds with more than one aromatic ring) can be found in the vast majority of aromatic plants, and have been associated with the plant's bioactive properties [4]. Medicinal plants and their phenolic compounds are thus strong candidates for the development of new drugs [5], having the advantages of worldwide availability, low price, and safety $[6,7]$. In fact, auto-medication with plants to cure diseases and alleviate pain was a recurrent practice from the beginning of human civilization $[8,9]$. Now, the rising levels of resistance to traditional antimicrobial therapies are widely recognized as a global issue and require the urgent development of new approaches to fight microbial infections. In this context, extracts from plant origin are a promising antimicrobial alternative worthy of further exploration [8-10].

Satureja montana L. and Origanum majorana L. are annual, medicinal, and aromatic plant species from the Lamiaceae family. Origanum majorana is a perennial plant originally native of 
the Mediterranean region but widely cultivated in many countries. Satureja montana is a plant native from the Mediterranean region and cultivated all over Europe, Russia, and Turkey [11,12]. Both are widely used in the Mediterranean diet, holding known anti-inflammatory, antibacterial, antifungal, and antioxidant properties [12-16]. Here we evaluated the antimicrobial activity of Satureja montana L. and Origanum majorana L. by studying their decoction extract against several Gram-positive and Gram-negative bacteria and Candida spp. The mechanisms of action and the phenolic compound composition of both plant decoctions were also characterized.

\section{Results}

\subsection{Antimicrobial Activity of Satureja montana L. and Origanum majorana L. Decoctions}

Decoctions of Satureja montana L. and Origanum majorana L. were screened for their antimicrobial activities against several Gram-positive and Gram-negative bacterial spp. and Candida spp. using the disc diffusion test (Table 1). Strong antimicrobial effects were observed for both plants against Staphylococcus aureus, Enterococcus faecalis, and Klebsiella pneumoniae and for Origanum majorana against $P$. aeruginosa. Moderate inhibitory activity was evidenced for both plant extracts against Streptococcus dysgalactiae and Satureja montana against Pseudomonas aeruginosa (Table 1). In general, these extracts were effective against both Gram-negative and Gram-positive bacteria, with the exception of Escherichia coli. The activity of the plant decoctions against Candida spp. was more limited, with only Satureja montana showing moderate activity against Candida tropicalis (Table 1).

Table 1. Antimicrobial activity of Satureja montana and Origanum majorana decoctions, determined by disc diffusion.

\begin{tabular}{ccc}
\hline Species & \multicolumn{2}{c}{ Antimicrobial Activity (Inhibition Zone, mm) } \\
\cline { 2 - 3 } & Satureja montana & Origanum majorana \\
\hline Gram-positive Bacteria & +++ & +++ \\
Staphylococcus aureus & +++ & +++ \\
Enterococcus faecalis & ++ & ++ \\
Streptococcus dysgalactiae & - & - \\
Gram-negative bacteria & ++ & +++ \\
Escherichia coli & +++ & +++ \\
Pseudomonas aeruginosa & - & - \\
Klebsiella pneumoniae & - & - \\
Yeast & ++ & - \\
Candida albicans & - & - \\
Candida tropicalis & - & - \\
Candida glabrata & - & \\
Negdida parapsilosis & Negative control &
\end{tabular}

(-) absence of halo, $(++)$ moderate halo $(8-10 \mathrm{~mm})$, and (+++) strong halo (greater than $11 \mathrm{~mm})$.

The minimum inhibitory concentration (MIC) and minimum bactericidal/fungicidal concentrations (MBC/MFC) of the plant decoctions were determined for the bacterial (one Gram-positive and one Gram-negative bacteria) and Candida tropicalis against which the highest antimicrobial activity was observed (Table 1). Satureja montana and Origanum majorana decoctions presented MIC and MBC values of $1.56 \mathrm{mg} / \mathrm{mL}$ (Table 2) against $S$. aureus and K. pneumoniae, suggesting that these extracts possess bactericidal features. Satureja montana decoction presented MIC and MFC values of $6.25 \mathrm{mg} / \mathrm{mL}$, exhibiting a lower antimicrobial effect comparatively to both bacteria tested. 
Table 2. Minimum inhibitory concentration (MIC) and minimum bactericidal/fungicidal concentration $(\mathrm{MBC} / \mathrm{MFC})(\mathrm{mg} / \mathrm{mL})$ of Satureja montana and Origanum majorana decoctions against S. aureus, K. pneumoniae, and C. tropicalis, determined using the Clinical and Laboratory Standards Institute (CLSI) broth microdilution method.

\begin{tabular}{ccccc}
\hline & \multicolumn{2}{c}{ Satureja montana } & \multicolumn{2}{c}{ Origanum majorana } \\
\hline Antibacterial & MIC & MBC & MIC & MBC \\
\hline Gram-positive bacterium & & & & \\
S. aureus & 1.56 & 1.56 & 1.56 & 1.56 \\
Gram-negative bacterium & & & & \\
K. pneumoniae & 1.56 & 1.56 & 1.56 & 1.56 \\
Antifungal & MIC & MFC & MIC & MFC \\
C. tropicalis & 6.25 & 6.25 & ND & ND \\
\hline
\end{tabular}

ND: Not determined.

\subsection{Mechanism of Action of Satureja montana and Origanum majorana Decoctions}

Flow cytometry and fluorescence microscopy techniques are usually used to determine the responses of cells to antimicrobial agents and to elucidate their mechanism of action. Live/dead staining, a dual staining procedure using SYTO9 and propidium iodide, allow the differentiation of live (green) and dead (red) cells, based on cell membrane integrity. Thus, the mechanism of action, and more specifically, the effect on cell viability and membrane integrity, of Satureja montana and Origanum majorana decoctions on $S$. aureus cells was evaluated, using a live/dead assay, by flow cytometry (Figure 1) and fluorescence microscopy (Figure 2). The extracts at their MIC $(1.56 \mathrm{mg} / \mathrm{mL})$ caused a considerable decrease in live cells and an increase in damaged cells $(p<0.05)$ after $3 \mathrm{~h}$ of exposure. After 5 and $24 \mathrm{~h}$, similar results were obtained for both extracts and control, with most of the cell population being undamaged (Figures 1 and 2).

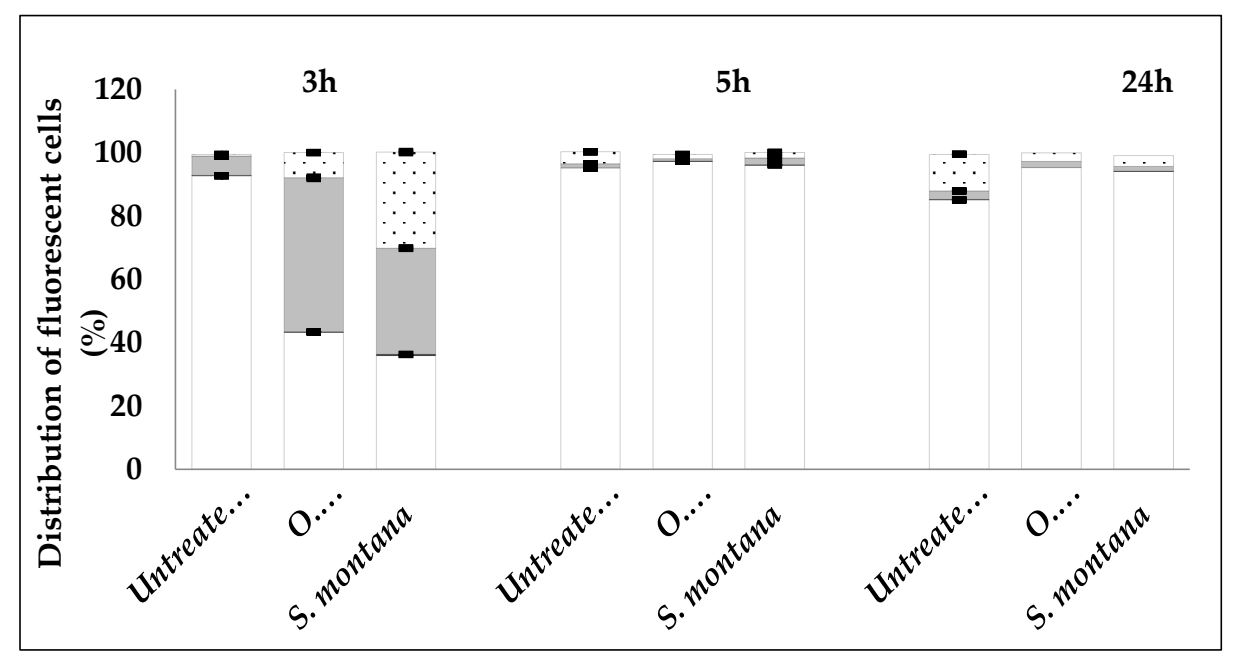

Figure 1. Membrane integrity of S. aureus ATCC 25923 after 3, 5, and 24 h exposure to Satureja montana and Origanum majorana decoctions at $1.56 \mathrm{mg} / \mathrm{mL}$. White bars with dots represent cell fragments or unstained cells; white bars represent cells with intact cell membranes; Gray bars represent cells with slight cell membrane permeabilization; Black bars represent cells with (complete) cell membrane permeabilization. The means \pm standard deviations for three independent assays are presented.

\subsection{Identification and Quantification of Phenolic Compounds}

Data obtained from the High Performance Liquid Chromatography system coupled to a Diode Array and Mass Spectrometer detectors (HPLC-DAD-ESI/MS; retention time, $\lambda$ max, pseudomolecular ions, main fragment ions in $\mathrm{MS}^{2}$, tentative identification, and quantification) of Satureja montana 
and Origanum majorana decoction extracts are shown in Table 3. Twenty-four phenolic compounds were identified, of which fifteen are flavonoids (luteolin, apigenin, and quercetin derivatives), and nine are phenolic acids derivatives ( $p$-coumaroyl, $p$-hydroxybenzoic, and caffeic acid derivatives: rosmarinic, salvianolic, and lithospermic acid). Interestingly, only six of the compounds identified are common to both plant extracts. While flavonoid compounds are present in higher numbers, phenolic compounds are present in higher quantity, mainly due to the high prevalence of rosmarinic acid (32\% in Satureja montana and 56\% in Origanum majorana).
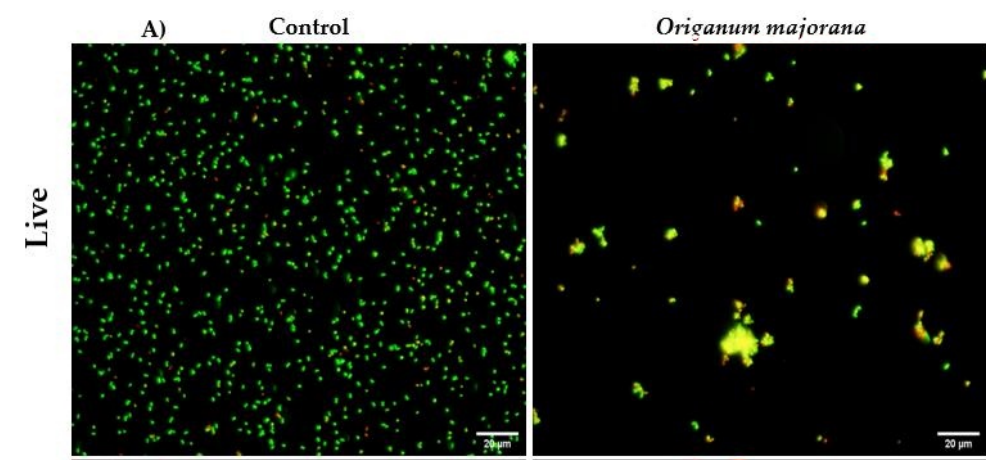

Satureia montana
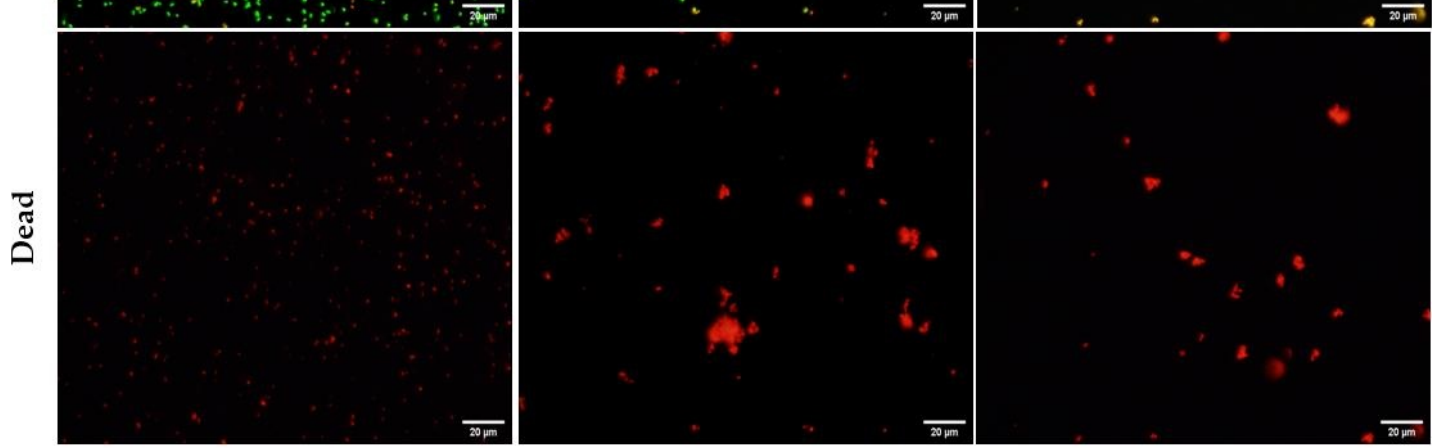

B)

Control

Origanum majorana

Satureja montana

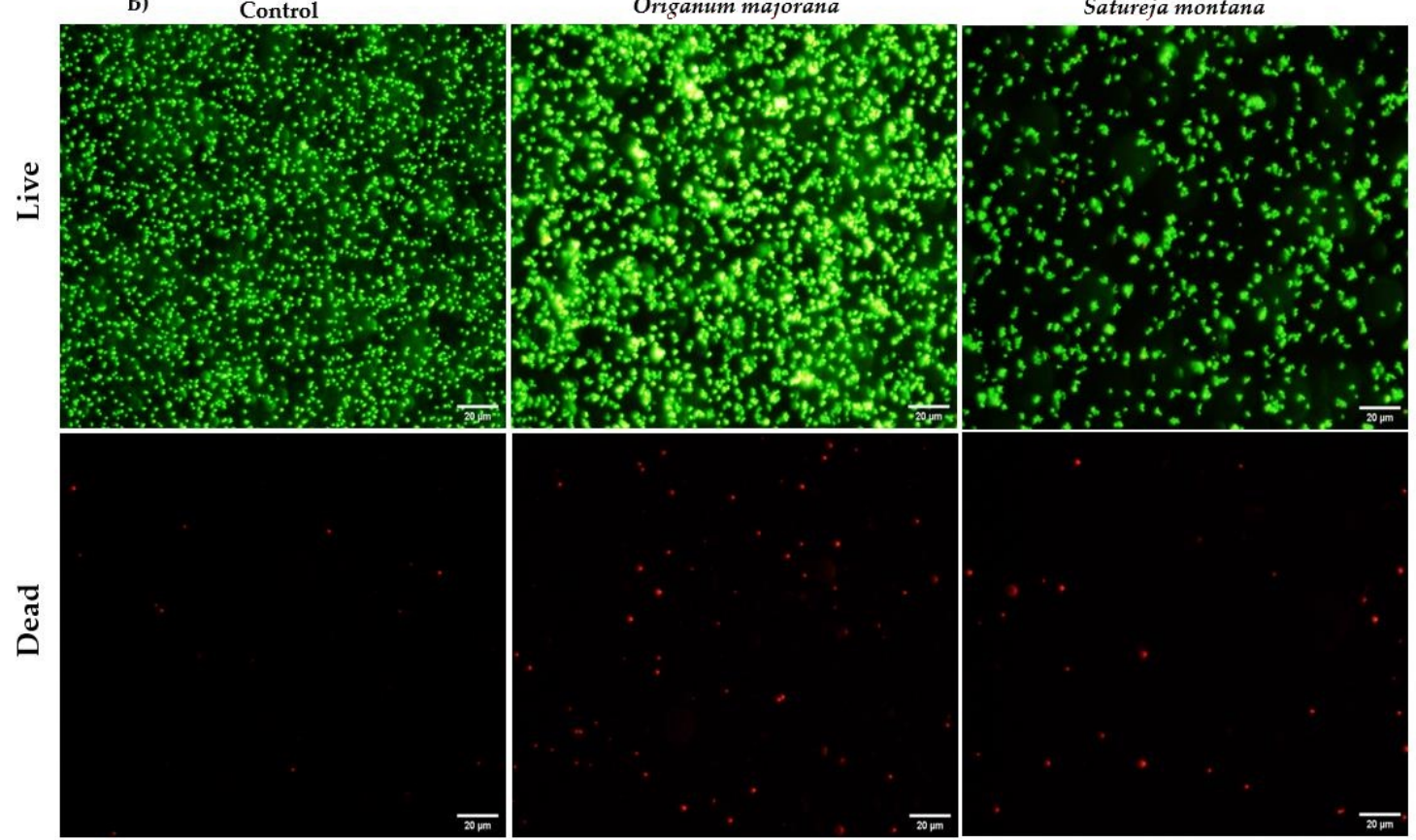

Figure 2. Live/dead cell viability images of S. aureus following $3 \mathrm{~h} \mathrm{(A)}$ and $24 \mathrm{~h}$ (B) exposure to 0 (control-untreated cells) and $1.56 \mathrm{mg} / \mathrm{mL}$ of Origanum majorana and Satureja montana decoctions. Live cells were stained with green and dead cells were stained with red. Magnification $400 \times$. Scale bar $=20 \mu \mathrm{m}$. 
Table 3. Retention time (Rt), wavelengths of maximum absorption in the visible region ( $\lambda \mathrm{max}$ ), mass spectral data, tentative identification, and quantification (mg/g of extract) of the phenolic compounds present in Satureja montana and Origanum majorana decoctions.

\begin{tabular}{|c|c|c|c|c|c|c|c|c|c|}
\hline \multirow{2}{*}{ Peak } & \multirow{2}{*}{$\begin{array}{c}\mathrm{Rt} \\
(\mathrm{min})\end{array}$} & \multirow{2}{*}{$\begin{array}{c}\lambda \max \\
(\mathrm{nm})\end{array}$} & \multirow{2}{*}{$\begin{array}{c}{[\mathrm{M}-\mathrm{H}]^{-}} \\
(\mathrm{m} / \mathrm{z})\end{array}$} & \multirow{2}{*}{ MS2 (m/z) } & \multirow{2}{*}{ Tentative Identification } & \multirow{2}{*}{$\begin{array}{l}\text { Reference Used for } \\
\text { Identification }\end{array}$} & \multicolumn{2}{|c|}{ Quantification (mg/g of Extract) } & \multirow{2}{*}{$\begin{array}{c}\text { Student's } \\
t \text {-Test } p \text {-Value }\end{array}$} \\
\hline & & & & & & & Satureja montana & Origanum majorana & \\
\hline 1 & 6.13 & 310 & 325 & $163(100)$ & $p$-Coumaroyl acid hexoside (A) & [17] & nd & $1.21 \pm 0.003$ & - \\
\hline 2 & 7.15 & 345 & 609 & $489(100), 399(10), 369(6)$ & Luteolin-C-hexoside-C-hexoside (B) & {$[17,18]$} & nd & $2.20 \pm 0.02$ & - \\
\hline 3 & 7.26 & 281 & 137 & $93(100)$ & $p$-Hydroxybenzoic acid (C) & $\mathrm{DAD} / \mathrm{MS}$ & $1.21 \pm 0.04$ & nd & - \\
\hline 4 & 9.55 & 336 & 593 & $503(30), 473(100), 383(12), 353(21)$ & Apigenin-6,8-di-C-hexoside isomer I (D) & {$[16,18]$} & $1.7 \pm 0.1$ & $7.3 \pm 0.2$ & $<0.001$ \\
\hline 5 & 9.89 & 335 & 593 & $503(31), 473(100), 383(11), 353(22)$ & Apigenin-6,8-di-C-hexoside isomer II (D) & {$[16,18]$} & $4.3 \pm 0.1$ & nd & - \\
\hline 6 & 11.73 & 346 & 637 & $285(100)$ & Luteolin-O-di-glucuronide (E) & {$[8,19]$} & nd & $3.8 \pm 0.2$ & - \\
\hline 7 & 12.41 & 339 & 637 & $285(100)$ & Luteolin-O-di-glucuronide (E) & {$[8,19]$} & $1.5 \pm 0.1$ & $2.14 \pm 0.02$ & $<0.001$ \\
\hline 8 & 14.31 & 350 & 477 & $301(100)$ & Quercetin-O-glucuronide (E) & $\mathrm{DAD} / \mathrm{MS}$ & $1.43 \pm 0.02$ & nd & - \\
\hline 9 & 14.41 & 339 & 623 & $461(100), 285(18)$ & Luteolin-O-hexoside-O-glucuronide (E) & $\mathrm{DAD} / \mathrm{MS}$ & nd & $1.58 \pm 0.04$ & - \\
\hline 10 & 14.57 & 342 & 637 & $461(100), 285(15)$ & Luteolin-O-di-glucuronide (E) & {$[8,19]$} & $1.27 \pm 0.01$ & nd & - \\
\hline 11 & 15.41 & 337 & 799 & $513(100), 285(15)$ & Luteolin derivative $(\mathrm{E})$ & $\mathrm{DAD} / \mathrm{MS}$ & nd & $6.874 \pm 0.002$ & - \\
\hline 12 & 15.81 & 340 & 623 & $461(100), 285(18)$ & Luteolin-O-hexoside-O-glucuronide (E) & $\mathrm{DAD} / \mathrm{MS}$ & $1.36 \pm 0.01$ & nd & - \\
\hline 13 & 17.25 & 340 & 579 & $285(100)$ & Luteolin-O-pentosyl-hexoside (E) & $\mathrm{DAD} / \mathrm{MS}$ & nd & $1.53 \pm 0.01$ & - \\
\hline 14 & 17.6 & 340 & 461 & $285(100)$ & Luteolin-O-glucuronide (E) & {$[16,17]$} & $3.8 \pm 0.1$ & $3.3 \pm 0.1$ & $<0.001$ \\
\hline 15 & 18.33 & 340 & 783 & $285(100)$ & Luteolin-O-di-glucuronyl-deoxyhexoside (E) & $\mathrm{DAD} / \mathrm{MS}$ & nd & $1.61 \pm 0.03$ & - \\
\hline 16 & 20.47 & 325 & 359 & $197(28), 179(35), 161(100)$ & Rosmarinic acid (F) & $\mathrm{DAD} / \mathrm{MS} ;[15,20]$ & $36.3 \pm 0.4$ & $52.4 \pm 0.2$ & $<0.001$ \\
\hline 17 & 23.57 & 340 & 461 & $\begin{array}{c}285(100) \\
537(29), 519(100)\end{array}$ & Luteolin-O-glucuronide (E) & {$[16,17]$} & $8.1 \pm 0.1$ & nd & - \\
\hline 18 & 23.88 & $288 / 322$ & 717 & $\begin{array}{c}493(10), 359(10), 339(6) \\
321(6), 295(5), 197(5) \\
179(5)\end{array}$ & Salvianolic acid B isomer I (F) & {$[18,19]$} & $0.683 \pm 0.001$ & $5.4 \pm 0.1$ & $<0.001$ \\
\hline 19 & 23.94 & 326 & 537 & $\begin{array}{c}493(50), 359(100), 313(8), \\
295(2), 269(2) \\
197(29), 179(34)\end{array}$ & Lithospermic acid A isomer I (F) & {$[8,21]$} & $16.9 \pm 0.2$ & nd & - \\
\hline 20 & 27.57 & $289 / 323$ & 493 & $\begin{array}{c}359(100), 313(10), 295(5) \\
269(5), 197(5), 179(5)\end{array}$ & Salvianolic acid $\mathrm{A}$ isomer I (F) & [21] & $20.0 \pm 0.7$ & $3.4 \pm 0.3$ & $<0.001$ \\
\hline 21 & 28.97 & $289 / 323$ & 493 & $\begin{array}{c}359(100), 313(10), 295(5), \\
269(5), 197(5), 179) \\
493(100), 359(42),\end{array}$ & Salvianolic acid A isomer II (F) & [21] & $2.692 \pm 0.003$ & nd & - \\
\hline 22 & 30.01 & 323 & 537 & $\begin{array}{c}313(10), 295(5), 269(5) \\
197(5), 179(5)\end{array}$ & Lithospermic acid A isomer II (F) & {$[8,21]$} & $2.752 \pm 0.001$ & nd & - \\
\hline 23 & 30.68 & 327 & 591 & $\begin{array}{c}283(100), 269(5) \\
537(29) 519(100) 493(10)\end{array}$ & Acacetin-O-glucuronide(G) & [16] & $4.39 \pm 0.03$ & nd & - \\
\hline \multirow[t]{4}{*}{24} & 32.64 & $287 / 321$ & 717 & $\begin{array}{c}\text { 359(10),339(6),321(6), } \\
295(5), 197(5), 179(5)\end{array}$ & Salvianolic acid B isomer II(F) & {$[18,19]$} & $4.7 \pm 0.1$ & nd & - \\
\hline & & & & & & Total phenolic acids & $85.22 \pm 1.03$ & $72.4 \pm 0.3$ & $<0.001$ \\
\hline & & & & & & Total flavonoids & $27.9 \pm 0.1$ & $20.4 \pm 0.2$ & $<0.001$ \\
\hline & & & & & & Total phenolic compounds & $113.1 \pm 0.9$ & $92.8 \pm 0.5$ & $<0.001$ \\
\hline
\end{tabular}

nd-not detected. Standard calibration curves: A—p-coumaric acid ( $\left.\mathrm{y}=301950 \mathrm{x}+6966.7, \mathrm{R}^{2}=0.9999\right) ; \mathrm{B}-$ luteolin-6-C-glucoside $\left(\mathrm{y}=4087.1 \mathrm{x}+72589, \mathrm{R}^{2}=0.9988\right) ; \mathrm{C}-p$-hydroxybenzoic acid $\left(y=208604 x+173056, R^{2}=0.9995\right) ; D-a p i g e n i n-6-C$-glucoside $\left(y=107025 x+61531, R^{2}=0.9989\right) ; E-q u e r c e t i n-3-O$-glucoside $\left(y=34843 x-160173, R^{2}=0.9998\right) ; F-$ rosmarinic acid $\left(y=191291 x-652903, R^{2}=0.999\right) ; G-a p i g e n i n-7-O$-glucoside $\left(y=10683 x-45794, R^{2}=0.9906\right)$. 


\section{Discussion}

The antimicrobial potential of plant species has been explored mostly via studies of their essential oils (EOs) $[12,13,22-34]$. Due to the toxic effect exhibited by EOs, it is of utmost importance to explore other plant-derived therapeutic alternatives. Several works report that solubility and bioactivity of plant-derived chemical compounds greatly depend on the extraction method used to obtain the compound. Decoction has proven to be one of the best methods for the efficient extraction of bioactive compounds, and the resultant plant extracts have been suggested as a potential substitute for EOs $[9,19]$. Here we evaluated the bioactivity of decoctions of Satureja montana and Origanum majorana compounds against several human pathogens. To the best of our knowledge, the bioactivity of these plant decoctions has not yet been evaluated. Aqueous extracts obtained by decoctions of Satureja montana and Origanum majorana demonstrated clear antimicrobial activity against Gram-negative and Gram-positive bacteria, with the exception of E. coli, and limited activity against Candida spp., with only $C$. tropicalis responding to treatment. These results are in accordance with previous studies with extracts of these plants obtained with other methods. Methanolic extracts of both Satureja montana [24] and Origanum majorana [27] presented a broad spectrum antimicrobial activity against microorganisms, such as S. aureus, E. coli, and C. albicans. Ćetković et al. tested several extracts of Satureja montana (petroleum ether, chloroform, ethyl acetate, and $n$-butanol) against pathogens, such as P. aeruginosa, E. coli, and S. aureus observing that Satureja montana presented antibacterial activity depending on the solvent used and that E. coli was not sensitive to any of the extracts studied, similar to what we observed here [12]. Mohamed et al. [31] saw strong in vitro activities of ethanol and water extracts of Origanum majorana against B. cereus, E. coli, S. enteritidis, and S. aureus. Crude extracts of Origanum majorana obtained using different polarity solvents (petroleum ether, dichloromethane, ethyl acetate, and aqueous fractions) also had good results against E. coli and K. pneumoniae [29].

MIC and MBC results from this work were very similar to those previously reported by Busatta et al. [28] and Miladi et al. [34] with Origanum majorana (MIC $=0.92$ and $0.782 \mathrm{mg} / \mathrm{mL}$ against K. pneumoniae and S. aureus, respectively) and Satureja montana EOs (MIC/MBC $=0.78 \mathrm{mg} / \mathrm{mL}$ against $S$. aureus). The MIC and MBC of Satureja montana obtained for Candida tropicalis were higher $(6.25 \mathrm{mg} / \mathrm{mL})$, demonstrating a weaker antifungal effect of this extract. Thus, Satureja montana and Origanum majorana decoction extracts were very effective, exerting an inhibitory effect against almost all bacteria tested and can be considered promising antibacterial agents, since decoction extracts, at $1.56 \mathrm{mg} / \mathrm{mL}$, completely inhibited the growth of S. aureus and K. pneumoniae.

The antimicrobial effect of Satrueja montana and Origanum majorana decoctions was evaluated over time by flow cytometry aiming to determine their possible mechanism of action on S. aureus ATCC 25923. S. aureus cells showed increased permeability to propidium iodide (PI) after $3 \mathrm{~h}$ exposure to both decoctions, demonstrating loss of membrane integrity. Membrane damage can lead to compromised cellular homeostasis and, consequently, to the disturbance of normal cell function [35]. However, the effect on S. aureus membrane seemed to be reversible, since no effect on membrane integrity was observed after longer exposures. This can result from the cell's capacity to repair some membrane lesions after injury and adapt to re-acquire their functionality by restoring their internal homeostasis and preventing cell death [36]. To increase and prolong the inhibitory effect of the decoctions, a new dose of plant extracts may be necessary after the first $3 \mathrm{~h}$ of treatment. By fluorescent microscopy, we observed some cell aggregation after 3 and $5 \mathrm{~h}$ of exposure to the plant extracts. Such effect was also reported by Annuk et al. [37] when using aqueous extracts of bearberry and cowberry leaves against Helicobacter pylori, which was justified by a modulatory effect on cell surface hydrophobicity. Another study observed the same aggregation effect on E. coli but found it to be unrelated to the antimicrobial activity of plant extracts [38]. We also observed that cell aggregation of S. aureus did not interfere positively with the bioactivity of Satureja montana and Origanum majorana decoctions since cells were able to restore their membrane integrity and, consequently, their functionality after exposure to both plant extracts. Overall, flow cytometry and fluorescence microscopy have shown that both plant extracts caused fast and reversible damages to the cell membranes of $S$. aureus. Therefore, 
although the specific mechanism of action is not yet well understood, it is possible that decoctions of Satureja montana and Origanum majorana are able to target the cell membranes by perturbing the cell membrane structures and architecture, especially in the first moments upon exposure.

The phenolic content of Satureja montana and Origanum majorana decoction extracts was also characterized in this study. Rosmarinic acid was found to be the main phenolic compound in both decoctions (36.3 mg/g in Satureja montana and $52.4 \mathrm{mg} / \mathrm{g}$ in Origanum majorana). This compound was also previously described as the main phenolic compound in Satureja parvifolia from India [20], Origanum majorana from Ireland [15], and Satureja parvifolia (Phil.) Epling [20]. Rosmarinic acid and caffeic acid derivatives have been extensively described in other Lamiaceae plant species $[8,9,19,21]$. Other caffeic acid derivatives were found in our decoctions, such as salvianolic and lithospermic acid derivatives. These derivatives were previously reported in Origanum majorana by Taamalli et al. [18] and Salvia officinalis (from the Lamiaceae family) by Martins et al. [19]. Additionally, we found salvianolic acid A and possibly lithospermic acid A present in our samples. While described in other Lamiaceae species, such as Melissa officinalis L. by Barros et al. [21] and Thymus vulgaris L. [8], this is, to the best of our knowledge, the first report of these compounds in Satureja montana and Origanum majorana. In terms of phenolic compounds, of all the caffeic acid derivatives mentioned, only two were detected in the decoction preparation of Origanum majorana. Although rosmarinic acid appears as the main phenolic compound in both samples, a greater variety of flavonoid compounds was identified in both samples. Three main aglycones were found, specifically luteolin, apigenin, and quercetin, which is in agreement with previous reports in other Satureja species, such as Satureja hortensis [16], Origanum majorana [17,18], and other Lamiaceae species $[8,9,19,21]$. Several luteolin derivatives were identified, among which we highlight luteolin-O-di-glucuronide as it is the first time it was found in Satureja montana and Origanum majorana, although previously described in other Lamiaceae species, such as Salvia officinalis and Thymus vulgare [8,19]. Finally, quercetin-O-glucuronide was the only quercetin derivative present in the studied samples, and here reported for the first time in Satureja montana.

\section{Materials and Methods}

\subsection{Preparation of Plant Extracts}

The dry leaves of Satureja montana L. (winter savory) and Origanum majorana L. (marjoram) were obtained from "Cantinho das Aromáticas", an organic farmer from Vila Nova de Gaia (Portugal), and further powdered ( 20 mesh) before the extraction procedure. Decoctions were performed by adding $200 \mathrm{~mL}$ of distilled water to the sample $(1 \mathrm{~g})$, heating (heating plate, VELP scientific), and boiling for $5 \mathrm{~min}$. The mixtures were left to stand for $5 \mathrm{~min}$ and then filtered under reduced pressure. The decoctions were frozen and further lyophilized (FreeZone 4.5, Labconco, Kansas City, MO, USA) to obtain a dry extract.

\subsection{Evaluation of Antimicrobial Activity}

\subsubsection{Disc Diffusion Assay}

The lyophilized decoctions were re-dissolved in water to obtain a stock solution of $50 \mathrm{mg} / \mathrm{mL}$. To evaluate the antimicrobial activity, different reference strains of bacteria and fungi were used, including the Gram-positive species S. aureus (ATCC 25923), E. faecalis (CECT 184), and Streptococcus dysgalactiae subsp. equisimilis (CECT 926); the Gram-negative species E. coli (ATCC 25922), K. pneumoniae (ATCC 11296), and P. aeruginosa (ATCC 10145); and the Candida species C. albicans (SC 5413), C. tropicalis (ATCC 750), C. glabrata (ATCC 2001), and C. parapsilosis (ATCC 20019). The antimicrobial effect was evaluated using the disc diffusion halo test. All bacterial strains were inoculated into $15 \mathrm{~mL}$ of Tryptic Soy Broth (TSB) from Tryptic Soy Agar (TSA) plates not older than 2 days, and grown for $24 \mathrm{~h}$ at $37^{\circ} \mathrm{C}$ in an orbital shaker at $120 \mathrm{rpm}$. Cells were harvested by centrifugation (for $5 \mathrm{~min}$ at $9500 \times g$ at $4^{\circ} \mathrm{C}$ ), re-suspended in TSB, adjusted to an optical density $(640 \mathrm{~nm})$ equivalent to $1 \times 10^{6}$ cells $/ \mathrm{mL}$, and then 
used in the subsequent assays. Candida spp. were inoculated in Sabouraud Dextrose Broth (SDB) liquid medium and incubated at $37^{\circ} \mathrm{C}$ and $120 \mathrm{rpm}$ during $24 \mathrm{~h}$, and then adjusted to a cellular concentration of $1 \times 10^{5}$ cells $/ \mathrm{mL}$. An aliquot of each strain $(300 \mu \mathrm{L})$ was spread in TSA and Sabouraud Dextrose Agar (SDA) plates to allow for the growth of bacteria and fungi, respectively. An aliquot $(25 \mu \mathrm{L})$ of each plant extract at $50 \mathrm{mg} / \mathrm{mL}$ was placed on a sterile blank disc. Sterile water was used as a negative control. The disks were placed on top of the bacteria and fungi plates, and the plates were incubated at $37^{\circ} \mathrm{C}$ during $24-48 \mathrm{~h}$. The inhibitory effects were determined by measuring the corresponding zones of inhibition (diameter of the halo of inhibition). The results were converted in a semi-quantitative scale: (-) absence of halo, (+) weak halo (3-7 mm), (++) moderate halo $(8-10 \mathrm{~mm})$, and (+++) strong halo (greater than $11 \mathrm{~mm}$ ). Experiments were repeated three times.

\subsubsection{Determination of MIC and MBC/MFC}

MIC values of Satureja montana and Origanum majorana decoction extracts were determined by microbroth dilution technique, against S. aureus, K. pneumoniae, and Candida tropicalis. MIC values were determined by serial two-fold dilution method, at concentrations ranging from $0.024 \mathrm{mg} / \mathrm{mL}$ to $12.5 \mathrm{mg} / \mathrm{mL}$, adjusting final cellular concentration to approximately $5 \times 10^{5}$ cells $/ \mathrm{mL}$. The 96 -well plates (Orange Scientific, Braine-1'Alleud, Belgium) were incubated at $37^{\circ} \mathrm{C}$ for $24-48 \mathrm{~h}$. Sample and cell-free controls were also included. MIC values were determined as the lowest concentrations at which no visible growth was observed. The bactericidal/fungicidal (MBC and MFC) effect of the decoctions was detected by comparison with positive controls (cells grown without extracts). Uninoculated media was used as a negative control to check for sterility. The number of viable cells was assessed by colony-forming unit (CFU) counting after $24 \mathrm{~h}$ of incubation at $37^{\circ} \mathrm{C}$. The $\mathrm{MBC} / \mathrm{MFC}$ values were considered the lowest concentrations at which no CFUs were counted. Experiments were carried out in triplicate and repeated on three independent occasions.

\subsection{Flow Cytometry}

\subsubsection{Sample Preparation}

An inoculum of $S$. aureus ATCC 25923 was adjusted to an $\mathrm{OD}_{640 \mathrm{~nm}}$ equivalent to $1 \times 10^{6}$ cells $/ \mathrm{mL}$ and kept at $37^{\circ} \mathrm{C}$ and $120 \mathrm{rpm}$. After $4 \mathrm{~h}$ of incubation, Origanum majorana and Satureja montana decoctions were added to a final concentration of $1.56 \mathrm{mg} / \mathrm{mL}$ and cells were grown at $37{ }^{\circ} \mathrm{C}$ and $120 \mathrm{rpm}$. Samples of $200 \mu \mathrm{L}$ were collected after 3, 5, and $24 \mathrm{~h}$ of antimicrobials exposure. The cells were centrifuged at $4{ }^{\circ} \mathrm{C}$ for $5 \mathrm{~min}$ and $9000 \times g$, and the pellets were re-suspended in $200 \mu \mathrm{L} \mathrm{of} \mathrm{NaCl} 0.9 \%$.

\subsubsection{Flow Cytometry Analysis}

Bacterial viability was assessed using a premixed stain composed of $1.67 \mathrm{mMSYTO} 9$ and $1.67 \mathrm{mM}$ propidium iodide (PI) (LIVE/DEAD ${ }^{\circledR}$ Baclight ${ }^{\mathrm{TM}}$ Bacterial Viability Kit). The premixed stain was added to the prepared samples of S. aureus ATCC 25923. The samples were analyzed after 10-15 min of incubation at room temperature in the dark. Flow cytometric analysis was performed on an EC800 Flow Cytometry Analyzer (Sony Biotechnology Inc., Champaign, IL, USA). Both SYTO9 and PI were excited by a diode blue laser $(488 \mathrm{~nm})$ and collected through a 530/50 $\mathrm{nm}$ bandpass filter in the FL1 channel and 615/30 nm bandpass filter in the FL4 channel, respectively. The sampling rate was $10 \mu \mathrm{L} / \mathrm{min}$, and the total number of events was set to 40,000 cells. Acquisition was performed using the EC800 software version 1.3.6 (Sony Biotechnology Inc., Champaign, IL, USA) and data analysis, gating, and compensation were carried out using Flow cytometry software FCS Express 6-RUO-version 6.05.0028 (de Novo Software, Glendale, CA, USA). Cells exposed to methanol (100\%, 10 min) were used as negative control. This assay was carried out on three different occasions. 


\subsubsection{Fluorescence Microscopy}

To confirm the results obtained by flow cytometry, $10 \mu \mathrm{L}$ of a stained sample was observed on an Olympus BX51 fluorescence microscope. Photomicroscopy was carried out using the Olympus CellSens imaging software.

\subsection{Identification and Quantification of Phenolic Compounds}

The phenolic profile was determined by LC-DAD-ESI/MSn (Dionex Ultimate 3000 UPLC, Thermo Scientific, San Jose, CA, USA). These compounds were separated and identified, as previously described by Bessada et al. [39]. The obtained extracts were re-dissolved at a concentration of $5 \mathrm{mg} / \mathrm{mL}$ prior to analysis. A double online detection was performed using a Diode Array Detector (DAD, 280,330 , and $370 \mathrm{~nm}$ as preferred wavelengths) and a mass spectrometer (MS). The MS detection was performed in negative mode, using a Linear Ion Trap LTQ XL mass spectrometer (Thermo Finnigan) equipped with an Electrospray ionization (ESI) source. The identification of the phenolic compounds was performed based on their chromatographic behavior and UV-vis and mass spectra by comparison with standard compounds, when available, and data reported in the literature, giving a tentative identification. Data acquisition was carried out with $\mathrm{Xcalibur}^{\circledR}$ data system (Thermo Scientific, San Jose, CA, USA). For quantitative analysis, a calibration curve for each available phenolic standard (apigenin-6-C-glucoside, apigenin-7-O-glucoside, luteolin-6-C-glucoside, $p$-coumaric acid, $p$-hydroxybenzoic acid, quercetin-3-O-glucoside, rosmarinic acid, Extrasynthèse, Genay, France) was constructed based on the UV-vis signal. For the identified phenolic compounds for which a commercial standard was not available, the quantification was performed using the calibration curve of the most similar available standard. The results were expressed as milligram/gram of extract.

\subsection{Statistical Analysis}

All samples of decoction were prepared and analyzed in triplicate. The phenolic characterization results were expressed as mean values and standard deviation (SD) and analyzed using a Student's $t$-test, with $\alpha=0.05$, performed with the SPSS v. 23.0 program.

\section{Conclusions}

Although the specific mechanisms of action of Satureja montana and Origanum majorana decoction are not yet well understood, new insights into their mode of action were provided in this study. The antimicrobial activity of Satureja montana and Origanum majorana decoction extracts seems to be attributed to cell membrane perturbation, resulting in the impairment of cell membrane integrity, especially in the first moments after exposure. Overall, this work revealed the bioactive potential of medicinal and aromatic plants showing that the decoctions of Satureja montana and Origanum majorana are rich in rosmarinic acid and show promise as antimicrobial agents. Further studies are needed to elucidate the in vivo efficacy of these decoctions, to assess their feasibility to be incorporated in formulations for antimicrobial purposes.

Author Contributions: Conceptualization, F.G., M.I.D., Â.L., L.B., M.E.R., I.C.F.R.F. and M.H.; methodology, F.G.; validation, F.G., M.I.D., I.C.F.R.F. and M.H.; formal analysis, F.G., M.I.D., and Â.L.; investigation, F.G., M.I.D., and Â.L.; data curation, F.G., M.I.D., and Â.L.; writing—original draft preparation, F.G. and M.I.D.; writing—review and editing, F.G., M.I.D., L.B., I.C.F.R.F. and M.H. All authors have read and agreed to the published version of the manuscript.

Funding: This study was supported by the Portuguese Foundation for Science and Technology (FCT) (grant number SFRH/BPD/84488/2012 and SFRH/BPD/93078/2013) under the scope of the strategic funding of UID/BIO/04469/2013 unit and COMPETE 2020 (POCI-01-0145-FEDER-006684) and BioTecNorte operation (NORTE-01-0145-FEDER-000004) funded by the European Regional Development Fund under the scope of Norte2020-Programa Operacional Regional do Norte. The authors are also grateful to FCT for financial support by national funds FCT/MCTES to CIMO (UIDB/00690/2020), and through the institutional scientific employment program-contract for Maria Inês Dias and Lillian Barros. FEDER-Interreg España-Portugal through project 0377_Iberphenol_6_E and TRANSCoLAB 0612_TRANS_CO_LAB_2_P. 
Acknowledgments: The authors thankful to Cantinho das Aromáticas Lda. for providing samples. We also thank Ana Rita Costa for their collaboration on English language revision.

Conflicts of Interest: The authors declare no conflict of interest.

\section{References}

1. Liu, R.H. Health-promoting components of fruits and vegetables in the diet. Adv. Nutr. Int. Rev. J. 2013, 4, 384S-392S. [CrossRef] [PubMed]

2. Qadir, M.A.; Shahzadi, S.K.; Bashir, A.; Munir, A.; Shahzad, S. Evaluation of phenolic compounds and antioxidant and antimicrobial activities of some common herbs. Int. J. Anal. Chem. 2017, 2017, 3475738. [CrossRef]

3. Cartea, M.E.; Francisco, M.; Soengas, P.; Velasco, P. Phenolic compounds in Brassica vegetables. Molecules 2011, 16, 251-280. [CrossRef] [PubMed]

4. Guimarães, R.; Sousa, M.J.; Ferreira, I.C.F.R. Contribution of essential oils and phenolics to the antioxidant properties of aromatic plants. Ind. Crops Prod. 2010, 32, 152-156. [CrossRef]

5. Shakya, A.K. Medicinal plants: Future source of new drugs. Int. J. Herb. Med. IJHM 2016, 59, 59-64.

6. Pour, M.A.; Sardari, S.; Eslamifar, A.; Azhar, A.; Rezvani, M.; Nazari, M. Cheminformatics-based anticoagulant study of traditionally used medicinal plants. Iran. Biomed. J. 2017, 21, 400-405. [CrossRef]

7. Majumder, S.; Sigamani1, A.; Rahman, T.; Rahmatullah, M. Exploring phytochemicals as alternatives to antimicrobials-Prospects and potentials. World J. Pharm. Pharm. Sci. 2020, 9, 1802-1813 1020959/wjpps20201.

8. Martins, N.; Barros, L.; Santos-Buelga, C.; Silva, S.; Henriques, M.; Ferreira, I.C.F.R. Decoction, infusion and hydroalcoholic extract of cultivated thyme: Antioxidant and antibacterial activities, and phenolic characterisation. Food Chem. 2015, 167, 131-137. [CrossRef]

9. Martins, N.; Barros, L.; Santos-Buelga, C.; Henriques, M.; Silva, S.; Ferreira, I.C.F.R. Decoction, infusion and hydroalcoholic extract of Origanum vulgare L.: Different performances regarding bioactivity and phenolic compounds. Food Chem. 2014, 158, 73-80. [CrossRef]

10. Martins, N.; Ferreira, I.C.F.R.; Barros, L.; Carvalho, A.M.; Henriques, M.; Silva, S.C. Plants used in folk medicine: The potential of their hydromethanolic extracts against Candida species. Ind. Crops Prod. 2015, 66, 62-67. [CrossRef]

11. Banchio, E.; Bogino, P.C.; Zygadlo, J.; Giordano, W. Plant growth promoting rhizobacteria improve growth and essential oil yield in Origanum majorana L. Biochem. Syst. Ecol. 2008, 36, 766-771. [CrossRef]

12. Ćetković, G.S.; Čanadanović-Brunet, J.M.; Djilas, S.M.; Tumbas, V.T.; Markov, S.L.; Cvetković, D.D. Antioxidant potential, lipid peroxidation inhibition and antimicrobial activities of Satureja montana L. subsp. kitaibelii extracts. Int. J. Mol. Sci. 2007, 8, 1013-1027. [CrossRef]

13. Serrano, C.; Matos, O.; Teixeira, B.; Ramos, C.; Neng, N.; Nogueira, J.; Nunes, M.L.; Marques, A. Antioxidant and antimicrobial activity of Satureja montana L. extracts. J. Sci. Food Agric. 2011, 91, 1554-1560. [CrossRef]

14. Roby, M.H.H.; Sarhan, M.A.; Selim, K.A.H.; Khalel, K.I. Evaluation of antioxidant activity, total phenols and phenolic compounds in thyme (Thymus vulgaris L.), sage (Salvia officinalis L.), and marjoram (Origanum majorana L.) extracts. Ind. Crops Prod. 2013, 43, 827-831. [CrossRef]

15. Hossain, M.B.; Camphuis, G.; Aguiló-Aguayo, I.; Gangopadhyay, N.; Rai, D.K. Antioxidant activity guided separation of major polyphenols of marjoram (Origanum majorana L.) using flash chromatography and their identification by liquid chromatography coupled with electrospray ionization tandem mass spectrometry. J. Sep. Sci. 2014, 37, 3205-3213. [CrossRef] [PubMed]

16. López-Cobo, A.; Gómez-Caravaca, A.M.; Švarc-Gajić, J.; Segura-Carretero, A.; Fernández-Gutiérrez, A. Determination of phenolic compounds and antioxidant activity of a Mediterranean plant: The case of Satureja montana subsp. kitaibelii. J. Funct. Foods 2015, 18, 1167-1178. [CrossRef]

17. Kaiser, A.; Carle, R.; Kammerer, D.R. Effects of blanching on polyphenol stability of innovative paste-like parsley (Petroselinum crispum (Mill.) Nym ex A. W. Hill) and marjoram (Origanum majorana L.) products. Food Chem. 2013, 138, 1648-1656. [CrossRef] [PubMed]

18. Taamalli, A.; Arráez-Román, D.; Abaza, L.; Iswaldi, I.; Fernández-Gutiérrez, A.; Zarrouk, M.; Segura-Carretero, A. LC-MS-based metabolite profiling of methanolic extracts from the medicinal and aromatic species Mentha pulegium and Origanum majorana. Phytochem. Anal. 2015, 26, 320-330. [CrossRef] 
19. Martins, N.; Barros, L.; Santos-Buelga, C.; Henriques, M.; Silva, S.; Ferreira, I.C.F.R. Evaluation of bioactive properties and phenolic compounds in different extracts prepared from Salvia officinalis L. Food Chem. 2015, 170, 378-385. [CrossRef]

20. Cabana, R.; Silva, L.R.; Valentão, P.; Viturro, C.I.; Andrade, P.B. Effect of different extraction methodologies on the recovery of bioactive metabolites from Satureja parvifolia (Phil.) Epling (Lamiaceae). Ind. Crops Prod. 2013, 48, 49-56. [CrossRef]

21. Barros, L.; Dueñas, M.; Dias, M.I.; Sousa, M.J.; Santos-Buelga, C.; Ferreira, I.C.F.R. Phenolic profiles of cultivated, in vitro cultured and commercial samples of Melissa officinalis L. infusions. Food Chem. 2013, 136, 1-8. [CrossRef]

22. Kundaković, T.; Stanojković, T.; Kolundžija, B.; Marković, S.; Šukilović, B.; Milenković, M.; Lakušić, B. Cytotoxicity and antimicrobial activity of the essential oil from Satureja montana subsp. pisidica (Lamiceae). Nat. Prod. Commun. 2014, 9, 569-572.

23. de Lima Marques, J.; Volcão, L.M.; Funck, G.D.; Kroning, I.S.; da Silva, W.P.; Fiorentini, Â.M.; Ribeiro, G.A. Antimicrobial activity of essential oils of Origanum vulgare L. and Origanum majorana L. against Staphylococcus aureus isolated from poultry meat. Ind. Crops Prod. 2015, 77, 444-450. [CrossRef]

24. Kremer, D.; Košir, I.J.; Končić, M.Z.; Čerenak, A.; Potočnik, T.; Srečec, S.; Randić, M.; Kosalec, I. Antimicrobial and antioxidant properties of Satureja montana L. and S. subspicata Vis. (Lamiaceae). Curr. Drug Targets 2015, 16, 1-11. [CrossRef] [PubMed]

25. Radaelli, M.; da Silva, B.P.; Weidlich, L.; Hoehne, L.; Flach, A.; da Costa, L.A.M.A.; Ethur, E.M. Antimicrobial activities of six essential oils commonly used as condiments in Brazil against Clostridium perfringens. Braz. J. Microbiol. 2016, 47, 424-430. [CrossRef] [PubMed]

26. Btissam, R.; Fatima, E.M.; Kamal, E.; Hassane, G.; Mohamed, N. Composition and antibacterial activity of hydro-alcohol and aqueous extracts obtained from the Lamiaceae family. Pharmacogn. J. 2017, 10, 81-91. [CrossRef]

27. Leeja, L.; Thoppil, J.E. Antimicrobial activity of methanol extract of Origanum majorana L. (Sweet marjoram). J. Environ. Biol. 2007, 28, 145-146.

28. Busatta, C.; Vidal, R.S.; Popiolski, A.S.; Mossi, A.J.; Dariva, C.; Rodrigues, M.R.A.; Corazza, F.C.; Corazza, M.L.; Vladimir Oliveira, J.; Cansian, R.L. Application of Origanum majorana L. essential oil as an antimicrobial agent in sausage. Food Microbiol. 2008, 25, 207-211. [CrossRef]

29. Abdel-Massih, R.; Abdou, E.; Baydoun, E.; Daoud, Z. Antibacterial activity of the extracts obtained from Rosmarinus officinalis, Origanum majorana, and Trigonella foenum-graecum on highly drug-resistant gram negative bacilli. J. Bot. Hindawi Publ. Corp. 2010, 1-8. [CrossRef]

30. Kozłowska, M.; Laudy, A.E.; Starościak, B.J.; Napiórkowski, A.; Chomicz, L.; Kazimierczuk, Z. Antimicrobial and antiprotozoal effect of sweet marjoram (Origanum majorana L.). Acta Sci. Pol. 2010, 9, 133-141.

31. Mohamed, N.; Yasmen, S.; Nohir, G. Antimicrobial activity of water and ethanol marjoram (Origanum marjorana L.) extract. In The 6th Arab and 3rd International Annual Scientific Conference on: Development of Higher Specific Education Programs in Egypt and the Arab World in the Light of Knowledge Era Requirements; Faculty of Specific Education Mansoura University: Mansoura, Egypt, 2011.

32. Oliveira, T.L.C.; de Araújo Soares, R.; Ramos, E.M.; das Graças Cardoso, M.; Alves, E.; Piccoli, R.H. Antimicrobial activity of Satureja montana L. essential oil against Clostridium perfringens type A inoculated in mortadella-type sausages formulated with different levels of sodium nitrite. Int. J. Food Microbiol. 2011, 144, 546-555. [CrossRef] [PubMed]

33. Freire, J.M.; Cardoso, M.G.; Batista, L.R.; Andrade, M.A. Essential oil of Origanum majorana L., Illicium verum Hook. f. and Cinnamomum zeylanicum Blume: Chemical and antimicrobial characterization. Rev. Bras. Plantas Med. 2011, 13, 209-214. [CrossRef]

34. Miladi, H.; Ben Slama, R.; Mili, D.; Zouari, S.; Bakhrouf, A.; Ammar, E. Chemical composition and cytotoxic and antioxidant activities of Satureja montana L. essential oil and its antibacterial potential against Salmonella Spp. strains. J. Chem. 2013, 2013, 1-9. [CrossRef]

35. Blazek, A.D.; Paleo, B.J.; Weisleder, N. Plasma membrane repair: A central process for maintaining cellular homeostasis. Physiology 2015, 30, 438-448. [CrossRef] [PubMed]

36. Andrews, N.W.; Corrotte, M. Plasma membrane repair. Curr. Biol. 2018, 28, R392-R397. [CrossRef] [PubMed] 
37. Annuk, H.; Hirmo, S.; Türi, E.; Mikelsaar, M.; Arak, E.; Wadström, T. Effect on cell surface hydrophobicity and susceptibility of Helicobacter pylori to medicinal plant extracts. FEMS Microbiol. Lett. 1999, 172, 41-45. [CrossRef]

38. Voravuthikunchai, S.P.; Limsuwan, S. Medicinal plant extracts as anti-Escherichia coli O157:H7 agents and their effects on bacterial cell aggregation. J. Food Prot. 2006, 69, 2336-2341. [CrossRef]

39. Bessada, S.M.F.; Barreira, J.C.M.; Barros, L.; Ferreira, I.C.F.R.; Oliveira, M.B.P.P. Phenolic profile and antioxidant activity of Coleostephus myconis (L.) Rchb. f.: An underexploited and highly disseminated species. Ind. Crops Prod. 2016, 89, 45-51. [CrossRef]

(C) 2020 by the authors. Licensee MDPI, Basel, Switzerland. This article is an open access article distributed under the terms and conditions of the Creative Commons Attribution (CC BY) license (http://creativecommons.org/licenses/by/4.0/). 